INTERNATIONAL HIGHER EDUCATION Number 75 Spring 2014

Pages 21-22

\title{
Trends in Higher Education Regulation in sub-Saharan Africa
}

\author{
A. B. K. Kasozi \\ A. B. K. Kasozi is the founding Executive Director of Uganda's National Council \\ for Higher Education, which he steered for 10 years, from 2002 to 2013. E-mail: \\ abkkasozi@yahoo.com.
}

Since 1980, many sub-Saharan African countries have established government funded, but also semiautonomous, higher education regulatory agencies to help governments in the establishment, management, and supervising of higher education institutions. These agencies ensure that citizens receive quality higher education and institutions of higher learning help to generate new knowledge for the improvement of higher education, innovation systems, and economic development. Experience has shown that these agencies have minimized direct government micromanagement by acting as midway bodies between the state and the various higher education institutions of higher learning.

\section{Maintenance OF Quality}

Most sub-Saharan African English-speaking countries have delegated the responsibility of the maintenance of quality higher education in institutions of higher learning to these agencies. Current quality assurance mechanisms in most African countries have two major components: an external regulatory component based on a government-funded, but autonomous regulatory agency, and an 
institutional component within each university. The two components work together but the agency is the senior partner. The external (regulatory agency) sets and enforces uniform benchmarks for all university institutions. The internal unit, usually a quality-assurance office within the university, makes sure that the benchmarks are implemented. Benchmarks designed by, and specific to a given institution itself, could also be implemented within that institution.

\section{The EXTernal AND INTERnAl COMPONENT}

The regulatory frameworks at the external national levels are enforced by regulatory agencies which oversee the following areas: institutional accreditation, accreditation of individual programs, merit-based admissions into higher education institutions, credit accumulation and transfer, the quality of teaching staff; examination regulations, standardization of academic awards, research and publications, infrastructure of institutions, education facilities, and regulating cross-border higher education.

Regulatory agencies realize that the maintenance of quality is best done by the institution itself. Thus, institutions are asked to have an administrative unit to oversee quality in all the divisions of a university instituition. Universities are asked to carry out institutional audits on a regular schedule of about 3-5 years in east and southern Africa to assess performance. These internal audits include looking at the following areas: the general audits, institutional governance, the quality of teaching and learning, the quality of the academic staff, sufficiency of education facilities, research and publications, the quality of outputs, financial management, relations with the surrounding community, and other pertinent items. 
Regulatory agencies, in cooperation with institutions, are supposed to carry out an external institutional audit after an institution has completed the internal one. The aim of the external audit is to fill any quality gaps identified by the internal audit. Unfortunately, many regulatory agencies have not fulfilled their responsibilities of conducting external institutional audits.

\section{AcCreditation of Institutions and Programs}

Regulatory agencies have helped governments in the process of establishing universities. They have done this through a process known as institutional accreditation. Institutional accreditation-permitting institutions to exist and deliver higher education—is a tool of quality assurance and therefore relevant to higher education support. It is a rigorous but necessary exercise and covers all aspects of institutions ranging from land, staffing, educational facilities, governance, infrastructure, and the financial health of institutions.

All programs taught in universities in most of sub-Saharan Africa are accredited (or approved) by regulatory agencies. In a number of countries, agencies inspect the infrastructure and facilities, in which the programs will be taught, before accrediting a program. In others, the write-up of the program is considered sufficient. Regulatory agencies ensure that programs meet minimum requirements, are written in acceptable formats, and allow the students to get value for money.

\section{Instructional Autonomy and Academic Freedom}

Most universities decide that they should have the freedom to manage the governance of their institutions, without interference by external powers- 
including the owners of the university to hire and discharge staff, to design and teach academic programs, to admit students and discontinue them for good cause, to design and manage their budgets without interference by the owners of the university, to source for funds from anywhere possible, to make statutes and regulations that govern the activities of the university, and to be assured of protection based on a legal framework in the form of statutes or acts of parliament.

Academic freedom on the other hand is the individual freedom of university workers: to teach; do research; speak and publish without interference; penalty or intimidation from internal or external authorities. Many leaders of regulatory agencies accept all the above aspirations but see themselves as guardians of young institutions that need nurturing to maturity. Further, they also realize that there are many rogue institutions that should not be allowed to deliver inferior higher education.

\section{Intervention by Agencies Will Probably Shrink}

It is hoped that areas of intervention into universities by regulatory agencies will gradually shrink, as African universities develop capacity to deliver quality education. Until the many universities in sub-Saharan Africa deliver good quality higher education, regulatory agencies will remain relevant to steer the latter through the various storms of growth. This task is particulary vital, as many of the private institutions that have expanded in sub-Saharan Africa lack capacity to improve higher education. Many of them lack academic traditions, staff, infrastructure, research capacity, and what it takes to be a "universal" institution. Many are teaching institutions, their infrastructure meager, and 
financial bases very poor. They still need the guidance of their founders and the state represented by regulatory agencies to mature. When they become worldclass university institutions, the work of regulatory agencies should narrow depending on the political dimensions within each state. 